CARDIOLOGY UPDATE

\title{
Drug therapy in chronic heart failure
}

\author{
D B McKenzie, A J Cowley
}

Postgrad Med J 2003;79:634-642

Chronic heart failure is widely recognised as a common and escalating problem that causes major disability and often shortens life. Diuretics and digoxin have formed the mainstay of treatment for many years. Clinical trials have demonstrated that angiotensin converting enzymes and $\beta$ blockers, in selected patients, improve symptoms and reduce mortality. Angiotensin-ll antagonists and spironolactone may also have a role in certain individuals. Newer pharmacological approaches to the management of this complex disease are being developed, but await full evaluation.

See end of article for authors' affiliations

....................

Correspondence to: Dr Daniel McKenzie, Department of

Cardiovascular Medicine,

University Hospital, Derby

Road, Nottingham, NG7

2UH, UK; dan.mckenzie@ nottingham.ac.uk

Submitted

27 February 2003

Accepted 29 March 2003
$\mathrm{H}$ eart failure is a complex clinical syndrome, most simply defined as cardiac dysfunction associated with symptoms. Chronic heart failure (CHF) is a common debilitating illness, associated with a high mortality. It affects between 0.5 and 3 million people in the UK and $0.4 \%-2 \%$ of the total European population. ${ }^{1}$ Prevalence increases sharply with age, affecting $6 \%-10 \%$ of those older than 65 years. CHF is thus a disease of the elderly, due to the increasing longevity of our population, and increased survival rates from acute myocardial infarction. The average age at presentation is 76 years, with men being at a $75 \%$ higher risk of developing heart failure than women. ${ }^{2}$

\section{AETIOLOGY}

The most common cause of CHF is systolic dysfunction due to ischaemic heart disease. Other causes include hypertension and valvular disease. The aetiology of heart failure has changed over the years, reflecting successful treatment of valvular heart disease and improved survival of patients with hypertension and ischaemic heart disease. ${ }^{3}$ A frequent associated problem is atrial fibrillation, which may occur in up to $30 \%$ of new cases of heart failure. Altogether $20 \%-40 \%$ of CHF patients have normal systolic function and may have diastolic dysfunction, characterised by impaired ventricular relaxation, again more common in the elderly. ${ }^{5}$ Heart failure usually comprises a combination of both systolic and diastolic impairment.

\section{IMPACT OF CHRONIC HEART FAILURE}

Heart failure has a major impact on the quality of a patient's life, worse than angina or chronic airways disease. Despite considerable advances in the management of $\mathrm{CHF}$, it remains associated with a very poor prognosis, worse than many forms of cancer. Survival is variable and depends on, among other things, left ventricular ejection fraction, degree of neurohormonal activation, and functional class. In the Framingham cohort (1948-88), the median survival after the onset of heart failure was 1.7 years in men and 3.2 years in women. ${ }^{6}$ In severe heart failure, survival can be less than $50 \%$ at one year. ${ }^{7}$ Survival rates are far worse in clinical practice than those demonstrated in recent clinical trials, reflecting the highly selected nature of the patients randomised. ${ }^{8}$

The morbidity and healthcare costs of heart failure are enormous. ${ }^{3}$ In the UK CHF is estimated to cost $1 \%-2 \%$ of the total spent on health care, more than $£ 400$ million per year?; $75 \%$ of this expenditure is on hospitalisation, with CHF responsible for approximately $5 \%$ of all hospital admissions. Readmission for heart failure within three months of the initial hospital admission occurs in about one third of patients. The costs of drug treatment are comparatively small.

This review concerns the pharmacological treatments available for CHF patients, specifically those with left ventricular systolic dysfunction. Drug treatment should relieve symptoms, improve quality of life, slow disease progression, prevent hospital admission, and ideally prolong active life (box 1). Certain patient subgroups may also benefit from treatment with one of the

\footnotetext{
Abbreviations: $A C E$, angiotensin converting enzyme; ANP, atrial natriuretic peptide; BNP, brain natriuretic peptide; CARMEN, Carvedilol ACE Inhibitor Remodelling Mild CHF Evaluation; CHARM, Candesartan in Heart failure: Assessement of Reduction in Mortality and Morbidity; CHF, chronic heart failure; CIBIS, Cardiac Insufficiency Bisoprolol Study; COMET, Carvedilol or Metoprolol European Trial; CONSENSUS, Co-operative North Scandanavian Enalapril Survival Study; COPERNICUS, Carvedilol Prospective Randomised Cumulative Survival; ELITE, Evaluation of Losartan in The Elderly; ENABLE, Endothelin Antagonist Bosentan for Lowering Cardiac Events; IMPRESS, Inhibition of Metaloprotease by Ompatrilat in a Randomised Exercise and Symptoms Study of Heart Failure; MERIT-HF, Metoprolol CR/XL Randomised Intervention Trial in Heart Failure; NEP, neutral endopeptidase; NYHA, New York Heart Association; OPTIMAAL, Optimal Trial in Myocardial Infarction with the Angiotensin II Antagonist Losartan; OVERTURE, Ompatrilat Versus Enalapril Randomised Trial of Utility in Reducing Events; PRAISE, Prospective Randomised Amlodipine Survival Evaluation; RAAS, renin-angiotensin-aldosterone system; RALES, Randomised Aldactone Evaluation Study; RESOLVD, Randomised Evaluation of Strategies for Left Ventricular Dysfunction; SENIORS, Study of the Effects of Nebivolol Intervention on Outcome and Rehospitalisations in Seniors with Heart Failure; SOLVD, Studies of Left Ventricular Dysfunction; Val-HeFT, Valsartan Heart Failure Trial; V-HeFT, Vasodilator Heart Failure Trial
} 


\section{Box 1: Aims of drug treatment in CHF}

- Relieve symptoms.

- Improve quality of life.

- Slow progression of the disease.

- Prevent hospital admission.

- Reduce mortality.

various surgical and device treatment modalities available. Specific areas of current interest include cardiac resynchronisation therapy, implantable cardioverter defibrillators, and left ventricular assist devices.

\section{PATHOPHYSIOLOGY OF CHF}

Heart failure is a complex syndrome characterised by symptomatic impairment, usually with exercise intolerance due to breathlessness or fatigue, with associated evidence of cardiac dysfunction. Fluid retention may lead to pulmonary and peripheral oedema. The primary abnormality must be impaired cardiac function, which then sets off a train of compensatory mechanisms, some of which are ultimately detrimental, worsening symptoms and reducing survival.

\section{(1) Haemodynamic mechanisms}

In response to reduced cardiac output a number of central and peripheral changes occur (fig 1). Centrally there is increased left ventricular filling pressure due to venous vasoconstriction, which attempts to maintain cardiac output by the Frank-Starling mechanism. In addition, the resistance vessels constrict to maintain systemic arterial blood pressure in the face of a reduced cardiac output. Excessive cardiac filling pressures lead to an increase in lung stiffness and ultimately pulmonary oedema, causing breathlessness (fig 2). Heart rate increases and mechanisms to increase inotropic support are activated. Cardiac dilatation and hypertrophy also occur. Remodelling occurs when the ventricle dilates becoming less spherical, resulting in a further fall in ejection fraction.

Changes also occur in the periphery. Peripheral vasoconstriction varies in different vascular beds; resistance in the coronary and cerebral vessels changes little, whereas that to the skin, gut, kidneys, and skeletal muscle increases.

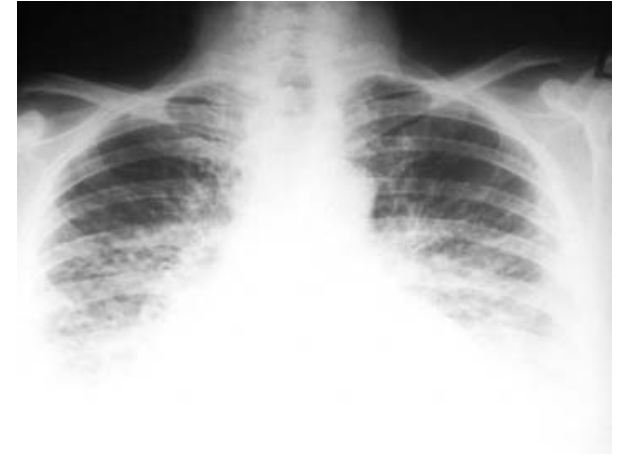

Figure 2 Radiograph showing cardiomegaly and pulmonary oedema.

Reduced blood flow to these tissues contributes to symptoms, particularly to skeletal muscle, which is a major cause of fatigue during exercise. Ultimately, the increased peripheral vascular resistance increases the load against which the heart ejects blood and this also has a detrimental effect on cardiac output.

\section{(2) Activation of neurohormonal mechanisms}

The mechanisms responsible for these haemodynamic changes are complex, but include the activation of neurohormonal systems. These systems are of considerable interest, as although they initially support cardiovascular homoeostasis, they ultimately appear to be harmful (fig 3).

The renin-angiotensin-aldosterone system (RAAS) is activated in heart failure, particularly in those patients taking diuretics, leading to increased concentrations of renin, angiotensin II, and aldosterone. Angiotensin II is a powerful vasoconstrictor of the systemic circulation that also inhibits vagal tone, promotes aldosterone production, and stimulates norepinephrine release from sympathetic nerve terminals. This leads to sodium and water retention, and potassium secretion via the kidneys and sweat glands. Angiotensin II also has important effects on cardiac myocytes and may contribute to the endothelial dysfunction seen in CHF patients. An important and often overlooked aspect of neurohormonal activation in heart failure is that there is a dialogue between the RAAS and the sympathetic nervous system, which is also activated. Increased activity of either system promotes the other.

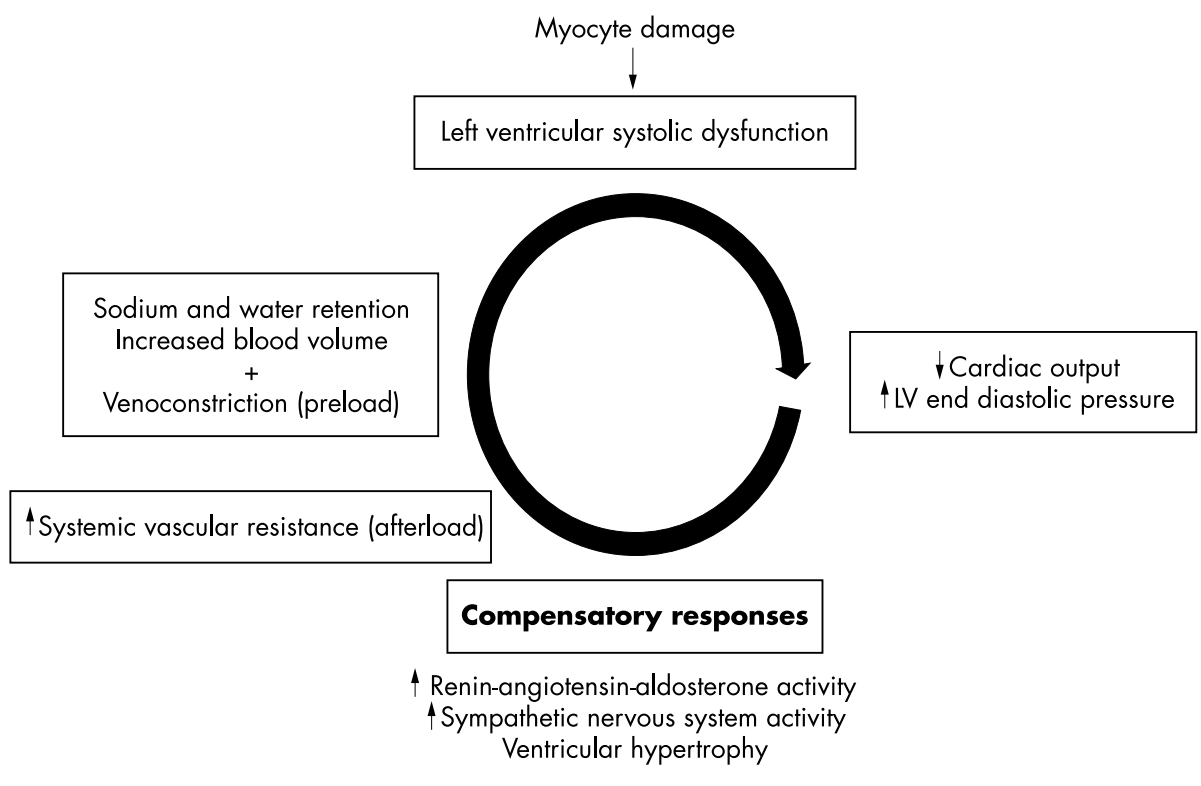

Figure 1 The chronic heart failure cycle. 


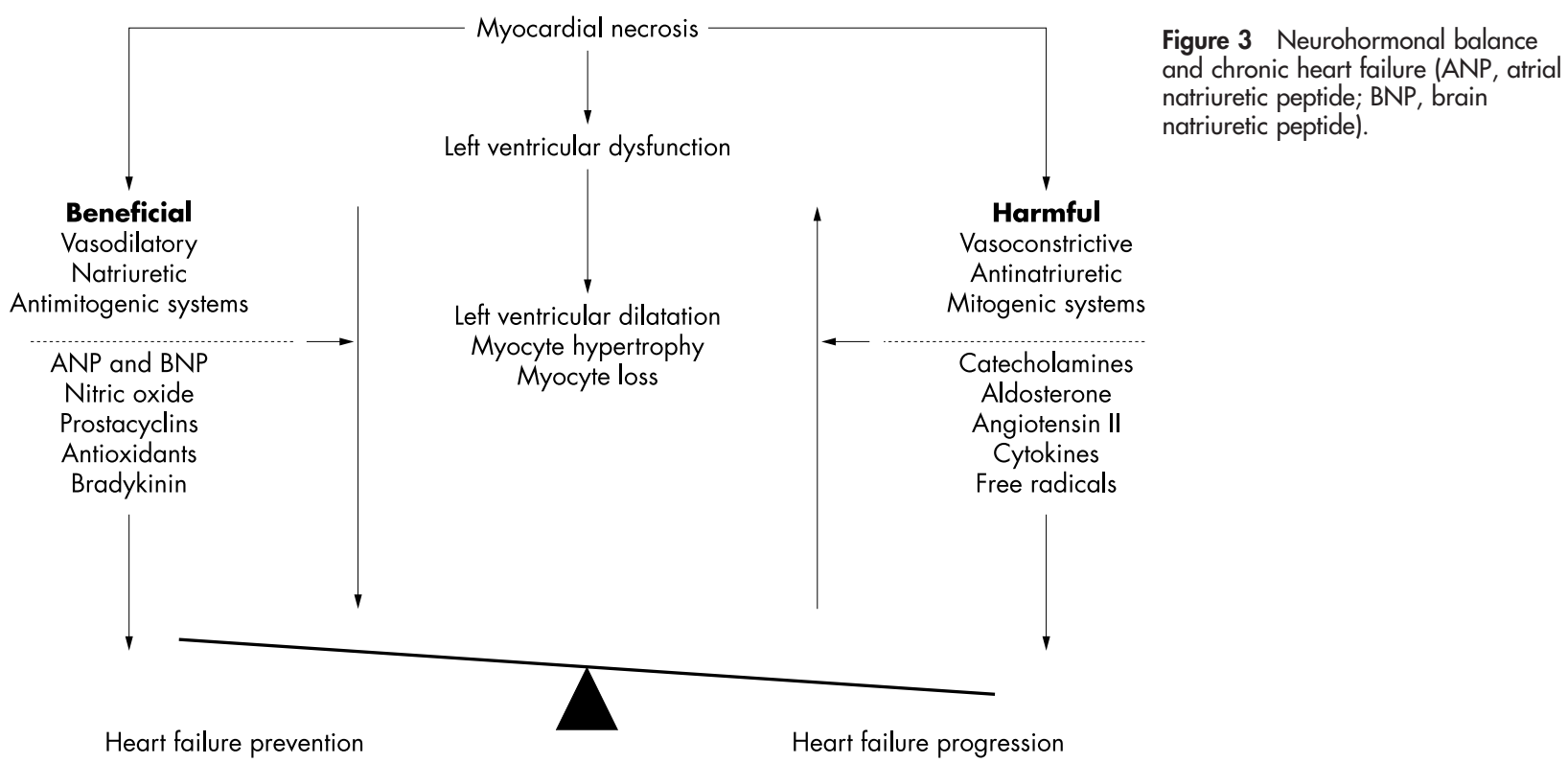

\section{(3) Sympathetic nervous system}

Heart failure patients have an activated sympathetic nervous system and elevated concentrations of circulating catecholamines. ${ }^{10}$ Clinically, this manifests as tachycardia and signs of peripheral vasoconstriction. The adrenergic activation is initially useful, as it helps to maintain an acceptable cardiac performance, but long term adrenergic activation is detrimental-it is associated with exercise intolerance, ${ }^{11}$ haemodynamic abnormalities, ${ }^{12}$ and increased mortality. ${ }^{10}$ Increased sympathetic tone can potentiate renin and angiotensin activity, leading to salt and water retention, arterial and venous constriction, and increased ventricular preload and afterload..$^{13}$ By increasing heart rate and promoting coronary vasoconstriction, catecholamine excess can also reduce myocardial blood flow. ${ }^{14}$ Norepinephrine is potently cardiotoxic and results in cardiac myocyte injury in concentrations found in the failing heart. ${ }^{15}$

\section{MEDICAL TREATMENT OF HEART FAILURE}

Considerable advances have been made in the drug treatment of heart failure over the past few decades. The basic principles of CHF treatment are:

- To reduce the workload on the heart during episodes of acute decompensation through rest, salt and water restriction, and drug treatment.

- To suppress the harmful effects of the neuroendocrine compensatory mechanisms (RAAS, sympathetic nervous system and, in the severe stages of disease, vasopressin release).

Basic advice to patients should include information about their condition, as well as the importance of stopping smoking, reducing salt and alcohol consumption, monitoring weight and fluid intake, and exercising regularly. It must be remembered that heart failure rarely occurs as an isolated disease process and that management is often complicated by coexisting factors. The prevalence of diabetes, chronic lung disease, renal dysfunction, depression, and peripheral vascular disease is relatively high in the heart failure population. Often, elderly patients have concomitant arthritis or neurological disorders. There is evidence that specialist heart failure clinics in primary or secondary care, ${ }^{16}$ specialist nurses in the community, ${ }^{17}$ and multidisciplinary teams can improve the quality of life of patients with CHF and reduce the need for hospital readmission. ${ }^{18}$

\section{PREVENTATIVE DRUG TREATMENTS}

Investigating the underlying cause of heart failure helps target effective treatment. Secondary prevention measures, including aspirin ${ }^{19}$ and intensive treatment of hypertension ${ }^{20}$ and dyslipidaemia, ${ }^{21}$ improve outcomes in patients with ischaemic heart disease, the commonest cause of CHF in the western world. Optimal blood glucose control in patients with diabetes should be encouraged using metformin, sulphonylureas and insulin as required. Warfarin may be beneficial in selected patients with heart failure-for example, those with atrial fibrillation or a left ventricular thrombus with no contraindication to chronic anticoagulation. Amiodarone ${ }^{22}$ and dofetilide ${ }^{23}$ appear safe and effective antiarrythmic agents in CHF patients with atrial fibrillation. It has also been recommended (though not evidence based) that all patients with CHF receive immunisation against influenza (annually) and pneumococcus (once). ${ }^{24}$

\section{DIURETICS}

Sodium and water retention is the hallmark of CHF and diuretics are mandatory treatment for patients with pulmonary or peripheral oedema. ${ }^{25}$ There are no alternative treatments that can replace diuretics once a patient has developed congestion. Loop diuretics revolutionised the treatment of heart failure, despite having detrimental effects on lipids, urate, and glucose metabolism. Loop (and thiazide) diuretics have not been evaluated in long term trials looking at mortality outcome, but improvements in cardiac function, exercise tolerance, and symptoms have been reported in a few short term studies. ${ }^{26} 27$ In severe heart failure, thiazide diuretics and metolazone have a synergistic effect with loop diuretics and may be used in combination. Diuretics activate the RAAS and should not be used in isolation, but should be given with an angiotensin converting enzyme (ACE) inhibitor.

Once fluid retention has resolved, treatment with diuretics should be maintained to prevent recurrent oedema, which may require frequent adjustments to the dose given. A clear explanation of their condition and the effect of diuretics, along with advice regarding weight monitoring and fluid 
intake, should enable informed patients to make appropriate changes to their diuretic dosage.

\section{VASODILATORS}

Improved survival in response to drug treatment was first shown in 1986 with the combination of isosorbide dinitrate and hydralazine. ${ }^{28}$ This combination has now been superseded by drugs that block the renin-angiotensin system. They may still have a role in patients who are intolerant of, or have contraindications to, ACE inhibitors. Other vasodilators, including the $\alpha$-blocker prazosin ${ }^{28}$ and the calcium channel antagonist amlodipine, ${ }^{29}$ had neutral effects on mortality in patients with CHF.

\section{DIGOXIN}

Digoxin is a mildly positive inotrope (at higher concentrations) that also increases vagal tone and suppresses renin secretion from the kidneys (at lower concentrations). There is no prospective controlled trial of the effects of the addition of digoxin on symptoms. However, drug withdrawal studies have shown that digoxin improves exercise capacity, symptoms, and the need for hospital admission both on its own ${ }^{30}$ and when combined with an ACE inhibitor. ${ }^{31}$ The Digitalis Investigation Group reported no mortality benefit in CHF patients on digoxin treatment over three years. ${ }^{32}$ Digoxin may be used to control the ventricular response rate in those CHF patients with atrial fibrillation. It would also be reasonable to use digoxin in those patients who remain symptomatic despite adequate treatment with diuretics, ACE inhibitors, and $\beta$-blockers. Digoxin toxicity may occur with serum concentrations greater than $2 \mathrm{ng} / \mathrm{ml}$, resulting in nausea and vomiting, cardiac arrhythmias, and neurological problems. Toxicity is more likely in the elderly and in those patients with renal impairment, hypothyroidism, and electrolyte disturbance or when used in combination with certain drugs, such as amiodarone, quinidine, or spironolactone. All other positive inotropes have had detrimental effects on outcome (see below).

\section{ANGIOTENSIN CONVERTING ENZYME INHIBITORS}

ACE inhibitors prevent the conversion of angiotensin I to angiotensin II, and also inhibit bradykinin degradation. ACE inhibitors shift the balance between the unwanted effects of angiotensin II and the beneficial vasodilatory and natriuretic effects of bradykinin (fig 3 ). The evidence that ACE inhibitors improve survival and symptomatic wellbeing in all grades of heart failure is now incontrovertible. ${ }^{73-35}$ It is well established that ACE inhibitors have beneficial effects in both the treatment and the prevention of heart failure, strongly supporting the neurohormonal theory.

In 1987, the double blind placebo controlled CONSENSUS study demonstrated a significant mortality benefit with enalapril (up to $40 \mathrm{mg} /$ day) in patients with severe heart failure $(26 \%$ enalapril $v 44 \%$ placebo, $\mathrm{p}=0.002) .{ }^{7}$ A significant improvement in the New York Heart Association (NYHA) classification, together with a reduction in heart size and a reduced requirement for other heart failure medication, was also observed in the enalapril group. The SOLVD trial provided further evidence of a mortality and morbidity reduction with enalapril (up to $20 \mathrm{mg} /$ day) in patients with left ventricular dysfunction $(\leqslant 35 \%)$ and mild to moderate CHF. ${ }^{36}$ Large, prospective, randomised double blind trials have demonstrated mortality and morbidity benefits in patients with symptomatic heart failure ${ }^{76}$, in those with asymptomatic left ventricular dysfunction, ${ }^{33}$ and in patients with left ventricular dysfunction complicating acute myocardial infarction. ${ }^{34} 3537$ They have also been shown to reduce the need for hospital admission and have proved to be a highly cost effective treatment. Higher doses (32.5-35 mg/day) of lisinopril are more effective than lower doses (2.5-5 mg/day) in reducing the combined endpoint of death and the need for hospital admission. ${ }^{38}$

Concerns about ACE inhibitors, including the risk of hypotension and renal dysfunction, may lead to a reluctance of some general practitioners to start the drugs, despite a good understanding of their benefits. ${ }^{39}$ Contraindications to the use of ACE inhibitors include angio-oedema or anaphylaxis on previous exposure, pregnancy, and bilateral renal artery stenosis. Many of the common adverse effects, including hypotension, renal dysfunction, and hyperkalaemia can be prevented by careful initiation and titration of treatment, with subsequent monitoring of blood pressure, urea, creatinine, and electrolytes. A dry cough occurs in about $10 \%$ of patients, and is the most common reason for ACE inhibitor withdrawal. It may improve with time, or by reducing the dose used.

\section{Angiotensin II blockers (ATI antagonists)}

Angiotensin II acts via a family of cell bound angiotensin receptors. The ATl receptor has been shown to mediate the detrimental effects of angiotensin II in patients with heart failure and angiotensin II antagonists block the ATl receptor. ACE is identical to kininase 2, a protease enzyme partly responsible for metabolism of the inflammatory mediator bradykinin. ACE inhibitors increase bradykinin levels, which may have beneficial vasodilator and fibrinolytic actions. Bradykinin is also thought to be responsible for the troublesome cough and angio-oedema seen in some patients. There is also evidence of breakthrough angiotensin II activity as a consequence of alternative non-ACE dependent pathways (for example, chymase) despite therapeutic doses of ACE inhibitors. ${ }^{40}{ }^{41}$ This is avoided with ATl antagonists by virtue of their selective action on the angiotensin II type I receptor. It was hoped that these effects would be beneficial in patients with heart failure. Two randomised studies in patients with mild to severe heart failure suggested that losartan (an angiotensin II antagonist) and enalapril have similar effects on haemodynamics and exercise capacity. ${ }^{42} 43$

The ELITE study was designed to assess drug safety and tolerability and randomised $722 \mathrm{CHF}$ patients over the age of 65 to losartan (50 mg once daily) or captopril (50 mg three times daily).$^{44}$ After 48 weeks, losartan demonstrated a lower incidence of side effects and drug withdrawal than captopril and a significant reduction in the secondary endpoint of all cause mortality, mainly due to a reduction in the incidence of sudden death. However, the study was too small to reliably assess survival effects. The complex RESOLVD study comparing candesartan and enalapril did not support these findings. ${ }^{45}$

ELITE II compared the effects of captopril and losartan in 3152 patients with mild to severe heart failure and demonstrated no difference in mortality between the drugs. ${ }^{46}$ The Val-HeFT trial tested the hypothesis that the combination of valsartan in addition to an ACE inhibitor and $\beta$-blocker would improve outcome. ${ }^{47}$ A total of 5010 patients with symptomatic CHF were randomised to valsartan or placebo and followed up for an average of 1.9 years. Valsartan did not reduce mortality, but did significantly reduce the combined endpoint of mortality and morbidity, mainly by reducing heart failure admissions. The greatest effect seemed to occur in those patients who were not receiving an ACE inhibitor at baseline, ${ }^{48}$ and those patients who received triple neurohormonal blockade (with an ACE inhibitor, a $\beta$-blocker, and valsartan) appeared to do poorly on subgroup analysis. These findings need further investigation and should be interpreted with caution.

OPTIMAAL enrolled 5477 patients over 50 years old with confirmed myocardial infarction and acute heart failure 
during the acute phase, or a new Q-wave anterior infarction or reinfarction. ${ }^{49}$ Patients were randomised to losartan (titrated up to $50 \mathrm{mg}$ once daily) or captopril (titrated up to $50 \mathrm{mg}$ three times daily) and followed up for a mean of 2.7 years. There was a non-significant trend towards reduced allcause mortality (the primary endpoint) in favour of captopril. Consequently ACE inhibitors should remain first choice treatment in patients following complicated myocardial infarction.

At present, no angiotensin II antagonist is licensed in the UK for use in heart failure, though valsartan has received its license in the United States. They may have a role in patients unable to tolerate unwanted effects with ACE inhibitors, particularly cough. The ongoing CHARM studies using candesartan may establish the role of the angiotensin II receptor blockers in $\mathrm{CHF}^{50}$

\section{$\beta$-BLOCKERS}

Prolonged neurohormonal activation has unwanted effects on the haemodynamics of the failing heart and also leads to apoptosis, arrhythmia, and reduced myocardial blood flow. For these reasons, drugs that interfere with the sympathetic nervous system have been extensively investigated in patients with CHF over the past 30 years. Over 15000 patients have now been enrolled in placebo controlled trials looking at the effects of $\beta$-blockade in patients with congestive heart failure. These studies have confirmed, that like ACE inhibitors, long term treatment with $\beta$-blockade can reduce symptoms, improve clinical status, and reduce the risk of death as well as the combined risk of death or hospitalisation..$^{51-53}$

Metoprolol is a second generation $\beta_{1}$-selective antagonist with no intrinsic sympathomimetic activity. In CHF patients, it has been demonstrated to improve cardiac function, left ventricular remodelling and capacity for exercise, and lessen the symptoms of heart failure. ${ }^{5455}$ The first placebo controlled, multicentre trial with a $\beta$-blocker in CHF was the Metoprolol in Dilated Cardiomyopathy trial. ${ }^{54}$ A total of 383 patients with symptomatic heart failure secondary to idiopathic dilated cardiomyopathy were randomised to metoprolol or placebo (up to $150 \mathrm{mg} /$ day in divided doses) for 12 to 18 months. There was a non-significant, $7.2 \%$ absolute risk reduction in the combined endpoint of all-cause mortality and patient deterioration requiring listing for heart transplantation $(20.1 \%$ placebo $v 12.9 \%$ metoprolol, $p=0.058)$ with a trend towards increased all-cause mortality in the metoprolol group. A larger placebo controlled mortality trial, the MERIT-HF study followed, randomising 3991 patients with CHF (NYHA II-IV) and an ejection fraction $<40 \%$ to placebo or metoprolol CR/XL (controlled release/extended release up to $200 \mathrm{mg}$ once daily-not licensed for use in patients with CHF in the UK) after a two week single blind run-in period..$^{52}$ The study was stopped early after a mean follow up of one year on the recommendation of the Independent Safety Committee due to a significant $3.8 \%$ absolute risk reduction in all-cause mortality in the metoprolol group $(7.2 \%$ v $11 \%$; adjusted $p=0.0062)$. Importantly, the average dose of metoprolol achieved in the MERIT-HF trial (159 mg) was larger than in the Metoprolol in Dilated Cardiomyopathy trial $(108 \mathrm{mg}$ ).

Carvedilol is a non-selective $\beta$-adrenoreceptor antagonist that also blocks $\alpha_{1}$-receptors. Unlike other $\beta$-blockers it exerts novel antioxidant and antiproliferative effects, which may contribute to its beneficial effects in patients with cardiac disease. The United States Carvedilol Heart Failure Trials Program was an amalgamation of four separate multicentre trials involving 1094 patients with mild, moderate, and severe heart failure and ejection fraction $<35 \%{ }^{51}$ Patients on stable background therapy were entered into one of the four placebo controlled studies on the basis of their ability to complete a six minute walk test. A predefined analysis of the combined data from all four trials demonstrated an overall mortality rate of $7.8 \%$ in the placebo group and $3.2 \%$ in the carvedilol group, during an average follow up of 6.5 months. The Australia/New Zealand Carvedilol Heart Failure Research Collaborative Group study enrolled patients on stable treatment including diuretics, an ACE inhibitor, and digoxin. ${ }^{56}{ }^{57}$ The first phase was a six month submaximal exercise trial that enrolled 415 patients with stable heart failure of an ischaemic aetiology after a two to three week open-label run-in phase to carvedilol or placebo (up to $50 \mathrm{mg} /$ day). The second phase, lasting an average of 19 months, demonstrated continued benefits on left ventricular dimensions and function and a $12.3 \%$ absolute risk reduction in the combined endpoint of mortality or hospitalisation $(62.5 \%$ placebo $v 50.2 \%$ carvedilol, $\mathrm{p}=0.02)$. While both the United States and Australia/New Zealand studies demonstrated a reduction in the combined endpoint of death and hospitalisation, only the United States study found a significant mortality reduction. Carvedilol is now licensed in the UK for reducing the clinical progression of heart failure and lowering the combined risk of morbidity and mortality.

The COPERNICUS Study Group recently published the results of an international multicentre trial looking at the effects of carvedilol on survival in severe CHF. ${ }^{58} \mathrm{~A}$ total of 2289 patients with heart failure symptoms at rest or on minimal exertion, on standard therapy, with an ejection fraction $<25 \%$, were randomised to carvedilol ( $n=1156$ ) or placebo $(n=1133)$ for a mean period of 10.4 months. Randomisation was stopped early in March 2000 on the recommendation of the Data and Safety Monitoring Board, because of a significant mortality benefit with carvedilol treatment. There was an estimated $7.1 \%$ absolute reduction in the risk of death in the carvedilol group at one year $(18.5 \%$ placebo $v 11.4 \%$ carvedilol, $\mathrm{p}=0.0014$ ). The annual mortality rate of $18.5 \%$ in the placebo group, compared for instance with $>60 \%$ in the CONSENSUS study, is lower than would be expected in non-selected patients. ${ }^{7}$

CIBIS-II randomised 2647 patients with moderate to severe heart failure (mostly NYHA class III) and a left ventricular ejection fraction of $35 \%$ or less, on standard therapy with diuretics and ACE inhibitors, to placebo or bisoprolol a $\left(\beta_{1}\right.$ selective $\beta$-blocker) up to $10 \mathrm{mg}$ a day..$^{53}$ The Data and Safety Monitoring Board stopped the trial early, after a mean follow up of 16 months, because bisoprolol demonstrated a significant mortality benefit. There was an absolute risk reduction of $5.5 \%$ in all-cause mortality with bisoprolol compared with placebo ( $11.8 \% v 17.3 \%, \mathrm{p}<0.0001)$, as well as significant reductions in hospitalisations for heart failure, and in the combined endpoint of cardiovascular deaths and hospital admission for cardiovascular events.

In summary, patients with stable symptomatic heart failure due to left ventricular systolic dysfunction should be considered for $\beta$-blocker therapy once treatment with diuretics and ACE inhibitors has been optimised. Established contraindications include decompensated heart failure, reversible airways obstruction, advanced heart block, and symptomatic bradycardia or hypotension. Initiation and uptitration of $\beta$-blockers can be difficult in heart failure patients, often requiring persistence and specialist knowledge to enable target doses to be achieved..$^{59}{ }^{60}$ The patient's heart rate, blood pressure, and clinical status should be monitored closely. It is important to reinforce that transient side effects are common and that the beneficial effects of $\beta$-blockers are sometimes only achieved after a number of months. In clinical practice withdrawal rates are greater than those seen among the highly selected patients enrolled in clinical trials. 
Currently there are a number of studies addressing some unanswered questions regarding treatment with $\beta$-blockers. Patients with symptomless left ventricular dysfunction are being enrolled in the CARMEN study with carvedilol. The SENIORS study will compare the effects of nebivolol, a novel $\beta_{1}$-selective blocker with vasodilatory properties, against placebo in elderly patients with heart failure. The COMET trial, comparing carvedilol and metoprolol is the first large scale, event driven trial comparing non-selective and selective $\beta$-blockers. Over 3000 patients have been randomised and the results of the study should be available in $2003 .{ }^{61}$

\section{SPIRONOLACTONE}

Aldosterone levels commonly remain elevated in patients on an ACE inhibitor and may contribute to the worsening of heart failure. Spironolactone, a potassium sparing diuretic, is a competitive antagonist of aldosterone and has been shown to have additional beneficial effects in patients already treated with an ACE inhibitor. ${ }^{62}$ The RALES trial randomised 1663 patients with severe heart failure who were on standard therapy with diuretics, an ACE inhibitor with or without digoxin, to spironolactone or placebo. Spironolactone (25$50 \mathrm{mg}$ a day) reduced absolute mortality by $11 \%$ (46\% v 35\% spironolactone) at a mean of two years. It also resulted in a significant decrease in the frequency of hospital admissions for worsening heart failure. Despite low rates of serious hyperkalaemia during the trial, the potential risk in clinical practice is greater, and renal function and potassium levels should therefore be monitored in patients on the combination of an ACE inhibitor and spironolactone.

\section{CALCIUM CHANNEL BLOCKERS}

The evidence that calcium channel blockers should be used for treating heart failure remains limited, but the non-rate limiting calcium antagonists appear safe and could be used to treat hypertension and angina in patients who also have CHF. The V-HeFT III study demonstrated a small symptomatic benefit with felodipine, ${ }^{63}$ while the PRAISE studies showed a neutral effect on mortality with amlodipine in patients with severe (NYHA III-IV) heart failure. ${ }^{29}$

\section{HARMFUL TREATMENTS}

It is important to be aware of medical treatments associated with adverse outcomes in CHF patients. Positive inotropes including the phosphodiesterase inhibitors milrinone, ${ }^{64}$ enoximone, ${ }^{65}$ and vesnarinone ${ }^{66}$ and xamoterol, an oral partial $\beta_{1^{-}}$ agonist ${ }^{67}$ all improved exercise tolerance and quality of life at the expense of increased early mortality. Flosequinan, ${ }^{68}$ an inodilator, and ibopamine, ${ }^{69}$ a dopamine agonist had similar outcomes. Class I antiarrythmic drugs should also be avoided and patients should be advised to limit their use of nonsteroidal anti-inflammatory agents that may aggravate heart failure.

\section{NEWER AGENTS}

There are a number of agents in the early stage of development, which may have a potential role in the management of CHF. The majority of these drugs attempt to restore the neurohormonal balance that is disrupted in patients with heart failure (fig 3). Atrial and brain natriuretic peptide (ANP and BNP) are hormones that have vasodilator, natriuretic, diuretic, and RAAS suppressing actions. ANP and BNP are degraded by the enzyme neutral endopeptidase (NEP or neprilysin), and inhibitors of this enzyme have been investigated as possible treatments for CHF. In early studies NEP inhibitors demonstrated beneficial haemodynamic and neurohormonal effects, and improvements in exercise tolerance. $^{70}{ }^{71}$ However toxicity related to one agent, ecadotril, stopped the further development of these agents. ${ }^{72}$ Drugs that inhibit both ACE and NEP, including omapatrilat, have also demonstrated beneficial haemodynamic and neurohormonal effects in CHF patients. ${ }^{73}$ Omapatrilat caused fewer adverse events than lisinopril in the prospective double blind IMPRESS trial. ${ }^{74}$ A total of 573 patients with NYHA II-IV heart failure, who were already receiving an ACE inhibitor, were randomised to $20 \mathrm{mg}$ lisinopril daily or $40 \mathrm{mg}$ omapatrilat daily for 24 weeks. There was no significant difference in the primary endpoint, the improvement in treadmill exercise time, between the two groups. OVERTURE was a prospective, double blind trial that randomised over 5500 CHF patients to omapatrilat or enalapril. ${ }^{75}$ There was no significant difference in the primary endpoint, death, or hospitalisation for worsening heart failure, between the two groups.

Endothelin-1, a 21 amino acid peptide is a very powerful vasoconstrictor with antinatriuretic, antidiuretic, and positive inotropic effects. Plasma concentrations of endothelin-1 are increased in heart failure and higher concentrations are associated with worse symptoms and clinical outcome, more impaired haemodynamics and reduced left ventricular systolic function. ${ }^{76-79}$ Some endothelin receptor antagonists, including tezosentan, demonstrated favourable acute and chronic haemodynamic effects. ${ }^{80-83}$ The ENABLE program randomised a total of 1613 patients in Europe and Australia

\section{Key points}

- Chronic heart failure (CHF) is an increasingly common problem and is associated with high morbidity and mortality.

- Basic treatment should include advice regarding the condition, salt and water balance, and the importance of exercise. Secondary prevention measures including aspirin and statins should also be used in CHF patients with underlying coronary artery disease.

- Diuretics are mandatory for heart failure patients with evidence of pulmonary or peripheral congestion. They improve symptoms, but have not been shown to reduce mortality.

- ACE inhibitors improve morbidity and mortality in CHF patients of all grades and also increase survival in patients with asymptomatic left ventricular systolic dysfunction.

- Angiotensin II blockers may be useful in patients intolerant of ACE inhibitors.

- $\beta$-Blockers (carvedilol, metoprolol CR/XL, and bisoprolol) improve survival in stable patients with $\mathrm{CHF}$ who have no contraindications and can tolerate the drugs.

- Spironolactone improves survival in selected NYHA IIIIV CHF patients who are stable on diuretics, an ACE inhibitor, a $\beta$-blocker $+/$ - digoxin.

- All of these drugs should be considered in patients with heart failure, but must be introduced and titrated carefully.

- Other treatments that may be considered in some patients include digoxin, hydralazine, and isosorbide dinitrate.

- A number of medications, including the positive inotrope xameterol, the phosphodiesterase inhibitors milrinone and enoximone, and the inodilator flosequinan are associated with an increase risk of early death and should be avoided in patients with CHF. 
(ENABLE 1) and North America (ENABLE 2), with NYHA class III-IV heart failure to the endothelin receptor antagonist bosentan $125 \mathrm{mg}$ twice daily or placebo. ${ }^{84}$ Disappointingly, bosentan was no better than placebo in reducing the combined endpoint of death or hospitalisation for worsening heart failure, but was associated with an early increased risk of worsening heart failure.

There is also interest in other agents including erythropoietin analogues, ${ }^{85}$ cytokine antagonists, ${ }^{86}$ lower dose enoximone combined with a $\beta$-blocker, and arginine vasopressin antagonists. ${ }^{87}$

\section{UNANSWERED QUESTIONS}

There is not yet clear evidence of benefit from any of these treatments in patients with diastolic dysfunction-that is, overt heart failure with preserved left ventricular function. The optimal treatment of patients with asymptomatic left ventricular dysfunction also remains unclear. There is a lack of evidence in elderly patients over 70 years old, who make up a large majority of patients with heart failure, ${ }^{1}$ and women remain under-represented in most heart failure trials. ${ }^{88}$ Further adequately powered trials enrolling patients typically

\section{Case report}

A 64 year old man suffered a non-Q-wave inferior wall myocardial infarction in 1994. He had a subsequent anterolateral ST elevation myocardial infarction in 1996 complicated by a ventricular fibrillation arrest and prolonged admission to the intensive treatment unit. After discharge he developed effort angina and subsequently left heart catheterisation and coronary angiography were undertaken. Severe three vessel coronary artery disease and global left ventricular systolic dysfunction were demonstrated. He went on to have quadruple bypass grafting and made a good recovery despite methycillin resistant Staphylococcus aureus wound infection. He was discharged home taking frusemide $80 \mathrm{mg}$ daily, enalapril $10 \mathrm{mg}$ twice daily, atorvastatin $20 \mathrm{mg}$ daily, and digoxin $125 \mathrm{mg}$ daily. Allopurinol $200 \mathrm{mg}$ daily was also prescribed for gout.

He did well until 2002 when he became increasingly breathless on exertion and was admitted in September with pulmonary oedema. His loop diuretic was changed to bumetanide $3 \mathrm{mg}$ daily, as this is more predictably absorbed from a congested gut than frusemide, and metolazone $2.5 \mathrm{mg}$ daily was added to increase his diuresis. After discharge he remained symptomatic and attempts were made to commence him on bisoprolol $1.25 \mathrm{mg}$ daily. However he had symptomatic hypotension with a systolic blood pressure of $80 \mathrm{~mm} \mathrm{Hg}$ and despite two attempts was unable to tolerate the drug. After a second admission with pulmonary oedema in October, spironolactone $25 \mathrm{mg}$ daily was added to his drugs with careful monitoring of his renal function and potassium. He had mild renal impairment (creatinine $136 \mu \mathrm{mol} / \mathrm{l}$ ), but his potassium remained within normal limits.

He remained limited on minimal exertion and was not considered suitable for heart transplantation. A 12-lead electrocardiogram demonstrated sinus rhythm, normal PR interval, left axis deviation, and left bundle branch block with a QRS duration of $180 \mathrm{~ms}$. A transthoracic echocardiogram demonstrated a dilated left ventricle with an end diastolic dimension of $7.8 \mathrm{~cm}$. There was severe global impairment of systolic function and septal motion was dyskinetic. He is currently awaiting implantation of a biventricular pacemaker system in an attempt to improve his symptoms. ${ }^{89}$

\section{Key references}

- Remme WJ, Swedberg K, Task Force for the Diagnosis and Treatment of Chronic Heart Failure. European Society of Cardiology. Guidelines for the diagnosis and treatment of chronic heart failure. Eur Heart $J$ 2001;22:1527-60.

- The CONSENSUS Trial Study Group. Effects of enalapril on mortality in severe congestive heart failure. Results of the Cooperative North Scandinavian Enalapril Survival Study (CONSENSUS). N Engl J Med 1987;316:1429-35.

- Anonymous. The Cardiac Insufficiency Bisoprolol Study II (CIBIS-II): a randomised trial. Lancet 1999;353:913.

- McMurray J, Cohen-Solal A, Dietz R, et al. Practical recommendations for the use of ACE inhibitors, betablockers and spironolactone in heart failure: putting guidelines into practice. European Journal of Heart Failure $2001 ; 3: 495-502$.

- McMurray J. Heart failure: we need more trials in typical patients. Eur Heart J 2000;21:699-700.

seen in daily clinical practice are needed to address these issues. ${ }^{8}$

\section{CONCLUSIONS}

The pharmacological treatment of patients with CHF should include preventative measures addressing the underlying cause of the disease. Loop (and/or thiazide) diuretics are mandatory in those patients with evidence of pulmonary or peripheral congestion. If tolerated, ACE inhibitors and $\beta$ blockers reduce mortality rates and can prevent the progression of symptoms and the need for hospital in CHF patients. Low dose spironolactone increases survival in patients with severe heart failure (NYHA III-IV) with ongoing symptoms despite standard therapy. Further evidence is needed before the role of angiotensin-II antagonists can be confirmed. Effective implementation of these treatments on an individual basis should greatly improve the outcome of patients who develop heart failure.

\section{Authors' affiliations}

D B McKenzie, A J Cowley, Department of Cardiovascular Medicine, University Hospital, Nottingham

\section{REFERENCES}

1 McMurray JJ, Stewart S. Epidemiology, aetiology, and prognosis of heart failure. Heart 2000:83:596-602.

2 Cowie MR, Wood DA, Coats AJ, et al. Incidence and aetiology of heart failure; a population-based study [comment]. Eur Heart J 1999;20:421-8.

3 Remme WJ, Swedberg K. Task Force for the Diagnosis and Treatment of Chronic Heart Failure European Society of Cardiology. Guidelines for the diagnosis and treatment of chronic heart failure. Eur Heart $J$ 2001;22:1527-60.

4 Vasan RS, Larson MG, Benjamin EJ, et al. Congestive heart failure in subjects with normal versus reduced left ventricular ejection fraction: prevalence and mortality in a population-based cohort. J Am Coll Cardiol 1999;33:1948-55.

5 Varela-Roman A, Gonzalez-Juanatey JR, Basante P, et al. Clinical characteristics and prognosis of hospitalised inpatients with heart failure and preserved or reduced left ventricular ejection fraction. Heart 2002;88:249-54

6 Ho KK, Anderson KM, Kannel WB, et al. Survival after the onset of congestive heart failure in Framingham Heart Study subjects. Circulation 1993;88:107-15. 
7 The CONSENSUS Trial Study Group. Effects of enalapril on mortality in severe congestive heart failure. Results of the Cooperative North Scandinavian Enalapril Survival Study (CONSENSUS). N Engl J Med 1987;316:1429-35.

8 McMurray J. Heart failure: we need more trials in typical patients. Eur Heart $J$ 2000:21:699-700.

9 Berry C, Murdoch DR, McMurray JJ. Economics of chronic heart failure. European Journal of Heart Failure 2001;3:283-91.

10 Cohn JN, Levine TB, Olivari MT, et al. Plasma norepinephrine as a guide to prognosis in patients with chronic congestive heart failure. N Engl J Med 1984;311:819-23

11 Francis GS, Goldsmith SR, Cohn JN. Relationship of exercise capacity to resting left ventricular performance and basal plasma norepinephrine levels in patients with congestive heart failure. Am Heart J 1982;104(4 pt 1):725-31.

12 Viquerat CE, Daly P, Swedberg K, et al. Endogenous catecholamine levels in chronic heart failure. Relation to the severity of hemodynamic abnormalities. Am J Med 1985;78:455-60

13 Sackner-Bernstein JD, Mancini DM. Rationale for treatment of patients with chronic heart failure with adrenergic blockade [erratum appears in JAMA 1996:275:686]. JAMA 1995;274:1462-7.

14 Frishman WH. Multifactorial actions of beta-adrenergic blocking drugs in ischemic heart disease: current concepts. Circulation 1983;67(6 pt 2):11 1-8.

15 Mann DL, Kent RL, Parsons B, et al. Adrenergic effects on the biology of the adult mammalian cardiocyłe. Circulation 1992;85:790-804.

16 Blue L, Lang E, McMurray JJ, et al. Randomised controlled trial of specialist nurse intervention in heart failure. BMJ 2001;323:715-8.

17 Stewart S, Marley JE, Horowitz JD. Effects of a multidisciplinary, home-based intervention on unplanned readmissions and survival among patients with chronic congestive heart failure: a randomised controlled study. Lancet 1999; 354:1077-83

18 Rich MW, Beckham V, Wittenberg C, et al. A multidisciplinary intervention to prevent the readmission of elderly patients with congestive heart failure [comment]. N Engl J Med 1995;333:1190-5.

19 Antithrombotic Trialists Collaboration. Collaborative meta-analysis of randomised trials of antiplatelet therapy for prevention of death, myocardial infarction, and stroke in high risk patients [comment] [erratum appears in BMJ 2002:324:141]. BMJ 2002:324:71-86.

20 SHEP Cooperative Research Group. Prevention of stroke by antihypertensive drug treatment in older persons with isolated systolic hypertension. Final results of the Systolic Hypertension in the Elderly Program (SHEP) [comment]. JAMA 1991;265:3255-64.

21 Kiekshus J, Pedersen TR, Olsson AG, et al. The effects of simvastatin on the incidence of heart failure in patients with coronary heart disease [comment] [erratum appears in Journal of Cardiac Failure 1998;4:367]. Journal of Cardiac Failure 1997:3:249-54

22 Doval HC, Nul DR, Grancelli HO, et al. Randomised trial of low-dose amiodarone in severe congestive heart failure. Grupo de Estudio de la Sobrevida en la Insuficiencia Cardiaca en Argentina (GESICA) [comment]. Lancet 1994;344:493-8.

23 Torp-Pedersen C, Moller M, Bloch-Thomsen PE, et al. Dofetilide in patients with congestive heart failure and left ventricular dysfunction. Danish Investigations of Arrhythmia and Mortality on Dofetilide Study Group [comment]. N Engl J Med 1999;341:857-65.

24 Department of Health. The national service framework for coronary heart disease. Available at: www.doh.gov.uk/nsf/coronary.htm, 2000.

25 Taylor SH. Refocus on diuretics in the treatment of heart failure. Eur Heart $J$ 1995; 16(suppl F):7-15.

26 Bayliss J, Norell M, Canepa-Anson R, et al. Untreated heart failure: clinica and neuroendocrine effects of introducing diuretics. British Heart Journal 1987:57:17-22.

27 Kaddoura S, Patel D, Parameshwar J, et al. Objective assessment of the response to treatment of severe heart failure using a 9-minute walk test on a patient-powered treadmill. Journal of Cardiac Failure 1996;2:133-9.

28 Cohn JN, Archibald DG, Ziesche S, et al. Effect of vasodilator therapy on mortality in chronic congestive heart failure. Results of a Veterans Administration Cooperative Study. N Engl J Med 1986;314:1547-52.

29 Packer M, O'Connor CM, Ghali JK, et al. Effect of amlodipine on morbidity and mortality in severe chronic heart failure. Prospective Randomized Amlodipine Survival Evaluation Study Group [comment]. N Engl J Med 1996:335:1107-14

30 Uretsky BF, Young JB, Shahidi FE, et al. Randomized study assessing the effect of digoxin withdrawal in patients with mild to moderate chronic congestive heart failure: results of the PROVED trial. PROVED Investigative Group. J Am Coll Cardiol 1993:22:955-62.

31 Packer $M$, Gheorghiade $M$, Young JB, et al. Withdrawal of digoxin from patients with chronic heart failure treated with angiotensin-converting-enzyme inhibitors. RADIANCE Study. N Engl J Med 1993;329:1-7.

32 The Digitalis Investigation Group. The effect of digoxin on mortality and morbidity in patients with heart failure. N Engl I Med 1997;336:525-33.

33 The SOLVD Investigators. Effect of enalapril on mortality and the development of heart failure in asymptomatic patients with reduced left ventricular ejection fractions. N Engl J Med 327:685-91.

34 The Acute Infarction Ramipril Efficacy (AIRE) Study Investigators. Effect of ramipril on mortality and morbidity of survivors of acute myocardial infarction with clinical evidence of heart failure. Lancet 1993;342:821-8.

35 Kober L, Torp-Pedersen C, Carlsen JE, et al. A clinical trial of the angiotensinconverting-enzyme inhibitor trandolapril in patients with left ventricular dysfunction after myocardial infarction. Trandolapril Cardiac Evaluation (TRACE) Study Group. N Engl J Med 1995;333:1670-6.

36 The SOLVD Investigators. Effect of enalapril on survival in patients with reduced left ventricular ejection fractions and congestive heart failure. N Engl J Med 1991;325:293-302.
37 Pfeffer MA, Braunwald E, Moye LA, et al. Effect of captopril on mortality and morbidity in patients with left ventricular dysfunction after myocardial infarction. Results of the survival and ventricular enlargement trial. The SAVE Investigators. N Engl J Med 1992;327:669-77.

38 Packer M, Poole-Wilson PA, Armstrong PW, et al. Comparative effects of low and high doses of the angiotensin-converting enzyme inhibitor, lisinopril, on morbidity and mortality in chronic heart failure. ATLAS Study Group. Circulation 1999;100:2312-8.

39 Houghton AR, Cowley AJ. Why are angiotensin converting enzyme inhibitors underutilised in the treatment of heart failure by general practitioners? Int I Cardiol 1997;59:7-10.

40 Wolny A, Clozel JP, Rein J, et al. Functional and biochemical analysis of angiotensin Il-forming pathways in the human heart. Cir Res 1997:80:219-27.

41 Petrie MC, Padmanabhan N, McDonald JE, et al. Angiotensin converting enzyme (ACE) and non-ACE dependent angiotensin II generation in resistance arteries from patients with heart failure and coronary heart disease. $J \mathrm{Am} \mathrm{Coll}$ Cardiol 2001;37:1056-61.

42 Dickstein K, Chang P, Willenheimer R, et al. Comparison of the effects of losartan and enalapril on clinical status and exercise performance in patients with moderate or severe chronic heart failure. J Am Coll Cardiol 1995; $26: 438-45$.

43 Lang RM, Elkayam U, Yellen LG, et al. Comparative effects of losartan and enalapril on exercise capacity and clinical status in patients with heart failure. The Losartan Pilot Exercise Study Investigators. I Am Coll Cardiol 1997;30:983-91.

44 Pitt B, Segal R, Martinez FA, et al. Randomised trial of losartan versus captopril in patients over 65 with heart failure (Evaluation of Losartan in the Elderly Study, ELITE) [comment]. Lancet 1997;349:747-52.

45 Tsuyuki RT, Yusuf S, Rouleau JL, et al. Combination neurohormonal blockade with ACE inhibitors, angiotensin II antagonists and beta-blockers in patients with congestive heart failure: design of the Randomized Evaluation of Strategies for Left Ventricular Dysfunction (RESOLVD) Pilot Study. Can J Cardiol 1997; 13:1166-74

46 Pitt B, Poole-Wilson PA, Segal R, et al. Effect of losartan compared with captopril on mortality in patients with symptomatic heart failure: randomised trial -the Losartan Heart Failure Survival Study ELITE II [comment]. Lancet 2000;355:1582-7.

47 Cohn JN, Tognoni G. A randomized trial of the angiotensin-receptor blocker Valsartan in chronic heart failure. N Engl J Med 2001;345:1667-75.

48 Cohn JN. Lessons learned from the valsartan-heart failure trial (Val-HeFT): angiotensin receptor blockers in heart failure. Am J Cardiol 2002;90:992-3.

49 Dickstein K, Kjekshus J. Comparison of the effects of losartan and captopril on mortality in patients after acute myocardial infarction: the OPTIMAAL trial design. Optimal Therapy in Myocardial Infarction with the Angiotensin II Antagonist Losartan. Am J Cardiol 1999:83:477-81.

50 Swedberg K, Pfeffer M, Granger C, et al. Candesartan in heart failureassessment of reduction in mortality and morbidity (CHARM): rationale and design. Charm-Programme Investigators. Journal of Cardiac Failure 1999:5:276-82.

51 Packer M, Bristow MR, Cohn JN, et al. The effect of carvedilol on morbidity and mortality in patients with chronic heart failure. US Carvedilol Heart Failure Study Group. N Engl I Med 1996;334:1349-55.

52 Anonymous. Effect of metoprolol CR/XL in chronic heart failure: Metoprolol CR/XL Randomised Intervention Trial in Congestive Heart Failure (MERTT-HF). Lancet 1999;353:2001-7.

53 Anonymous. The Cardiac Insufficiency Bisoprolol Study II (CIBIS-II): a randomised trial. Lancet 1999:353:9-13.

54 Waagstein F, Bristow MR, Swedberg K, et al. Beneficial effects of metoprolol in idiopathic dilated cardiomyopathy. Metoprolol in Dilated Cardiomyopathy (MDC) Trial Study Group. Lancet 1993;342:1441-6.

55 Waagstein $F$, Wahlqvist I, Andersson B, et al. Metoprolol prevents left ventricular dilatation and increases exercise ejection fraction to the same extent in idiopathic and ischemic cardiomyopathy. Eur Heart J 1998; 19(suppl):307(abstract).

56 Australia-New Zealand Heart Failure Research Collaborative Group. Effects of carvedilol, a vasodilator-beta-blocker, in patients with congestive heart failure due to ischemic heart disease. Circulation 1995:92:212-8.

57 Australia/New Zealand Heart Failure Research Collaborative Group. Randomised, placebo-controlled trial of carvedilol in patients with congestive heart failure due to ischaemic heart disease. Lancet 1997;349:375-80.

58 Packer M, Coats AJ, Fowler MB, et al. Effect of carvedilol on survival in severe chronic heart failure. N Engl J Med 2001:344:1651-8.

59 Eichhorn EJ, Bristow MR. Practical guidelines for initiation of beta-adrenergic blockade in patients with chronic heart failure. Am J Cardiol, 1997;79:794-8.

60 McMurray J, Cohen-Solal A, Dietz R, et al. Practical recommendations for the use of ACE inhibitors, beta-blockers and spironolactone in heart failure: putting guidelines into practice. European Journal of Heart Failure $2001 ; 3: 495-502$

61 Packer M. Current role of beta-adrenergic blockers in the management of chronic heart failure. Am J Med 2001;110(suppl 7A):81S-94S

62 Pitt B, Zannad F, Remme WJ, et al. The effect of spironolactone on morbidity and mortality in patients with severe heart failure. Randomized Aldactone Evaluation Study Investigators [comment]. N Engl J Med 1999;341:709-17.

63 Cohn JN, Ziesche S, Smith R, et al. Effect of the calcium antagonist felodipine as supplementary vasodilator therapy in patients with chronic heart failure treated with enalapril: V-HeFT III. Vasodilator-Heart Failure Trial (V-HeFT) Study Group. Circulation 1997;96:856-63.

64 Packer M, Carver JR, Rodeheffer RJ, et al. Effect of oral milrinone on mortality in severe chronic heart failure. The PROMISE Study Research Group.[comment]. N Engl J Med 1991;325:1468-75. 
65 Cowley AJ, Skene AM. Treatment of severe heart failure: quantity or quality of life? A trial of enoximone. Enoximone Investigators [comment]. British Heart Journal 1994;72:226-30.

66 Cohn JN, Goldstein SO, Greenberg BH, et al. A dose-dependent increase in mortality with vesnarinone among patients with severe heart failure. Vesnarinone Trial Investigators [comment]. N Engl J Med 1998;339:1810-6.

67 The Xamoterol in Severe Heart Failure Study Group. Xamoterol in severe heart failure [comment] [erratum appears in Lancet 1990;336:698]. Lancet 1990;336: 1-6.

68 Packer M, Rouleau J, Swedberg K, et al. Effect of flosequinon on survival in chronic heart failure: preliminary results of the PROFILE study [abstract]. Circulation 1993;88(suppl I):I-301.

69 Hampton JR, van Veldhuisen DJ, Kleber FX, et al. Randomised study of effect of ibopamine on survival in patients with advanced severe heart failure. Second Prospective Randomised Study of Ibopamine on Mortality and Efficacy (PRIME II) Investigators. Lancet 1997;349:971-7.

70 Northridge DB, Jardine AG, Alabaster CT, et al. Effects of UK 69 578: a novel atriopeptidase inhibitor. Lancet 1989;2:591-3.

71 Northridge DB, Currie PF, Newby DE, et al. Placebo-controlled comparison of candoxatril, an orally active neutral endopeptidase inhibitor, and captopril in patients with chronic heart failure. European Journal of Heart Failure 1999; 1:67-72.

72 Cleland JG, Swedberg K. Lack of efficacy of neutral endopeptidase inhibitor ecadotril in heart failure. The International Ecadotril Multi-centre Doseranging Study Investigators. Lancet 1998;351:1657-8.

73 McClean DR, Ikram H, Garlick AH, et al. The clinical, cardiac, renal, arterial and neurohormonal effects of omapatrilat, a vasopeptidase inhibitor, in patients with chronic heart failure. J Am Coll Cardiol 2000:36:479-86.

74 Rouleau JL, Pfeffer MA, Stewart DJ, et al. Comparison of vasopeptidase inhibitor, omapatrilat, and lisinopril on exercise tolerance and morbidity in patients with heart failure: IMPRESS randomised trial [comment] [erratum appears in Lancet 2000;356:1774]. Lancet 2000;356:615-20.

75 Packer M, Califf RM, Konstam MA, et al. Comparison of omapatrilat and enalapril in patients with chronic heart failure: the Omapatrilat Versus Enalapril Randomized Trial of Utility in Reducing Events (OVERTURE). Circulation 2002;106:920-6.

76 McMurray JJ, Ray SG, Abdullah I, et al. Plasma endothelin in chronic heart failure. Circulation 1992;85:1374-9.
77 Galatius-Jensen S, Wroblewski H, Emmeluth C, et al. Plasma endothelin in congestive heart failure: a predictor of cardiac death? Journal of Cardiac Failure 1996;2:71-6.

78 Love MP, McMurray JJ. Endothelin in heart failure: a promising therapeutic target? Heart 1997;77:93-4.

79 Petrie MC, McClure SJ, Love MP, et al. Novel neuropeptides in the pathophysiology of heart failure: adrenomedullin and endothelin-1. European Journal of Heart Failure 1999:1:25-9.

80 Kiowski W, Sutsch G, Hunziker $P$, et al. Evidence for endothelin-1-mediated vasoconstriction in severe chronic heart failure. Lancet 1995;346:732-6.

81 Cowburn PJ, Cleland JG, McArthur JD, et al. Short-term haemodynamic effects of $B Q-123$, a selective endothelin $E T(A)$-receptor antagonist, in chronic heart failure. Lancet 1998;352:201-2.

82 Torre-Amione G, Young JB, Durand J, et al. Hemodynamic effects of tezosentan, an intravenous dual endothelin receptor antagonist, in patients with class III to IV congestive heart failure. Circulation 2001; 103:973-80.

83 Givertz MM, Colucci WS, LeJemtel TH, et al. Acute endothelin A receptor blockade causes selective pulmonary vasodilation in patients with chronic heart failure [comment]. Circulation 2000;101:2922-7.

84 Kalra PR, Moon JC, Coats AJ. Do results of the ENABLE (Endothelin Antagonist Bosentan for Lowering Cardiac Events in Heart Failure) study spell the end for non-selective endothelin antagonism in heart failure? Int J Cardiol 2002;85:195-7.

85 Silverberg DS, Wexler D, Sheps D, et al. The effect of correction of mild anemia in severe, resistant congestive heart failure using subcutaneous erythropoietin and intravenous iron: a randomized controlled study. J Am Coll Cardiol 2001:37:1775-80.

86 Feldman AM, Combes A, Wagner D, et al. The role of tumor necrosis factor in the pathophysiology of heart failure. J Am Coll Cardiol 2000;35:537-44.

87 Udelson JE, Smith WB, Hendrix GH, et al. Acute hemodynamic effects of conivaptan, a dual $\mathrm{V}(1 \mathrm{~A})$ and $\mathrm{V}(2)$ vasopressin receptor antagonist, in patients with advanced heart failure. Circulation 2001;104:2417-23.

88 Richardson LG, Rocks M. Women and heart failure. Heart Lung 2001;30:87-97.

89 Walker S, Levy TM, Coats AJS, et al. Biventricular pacing in congestive cardiac failure. Eur Heart J 2000;21:884-9.

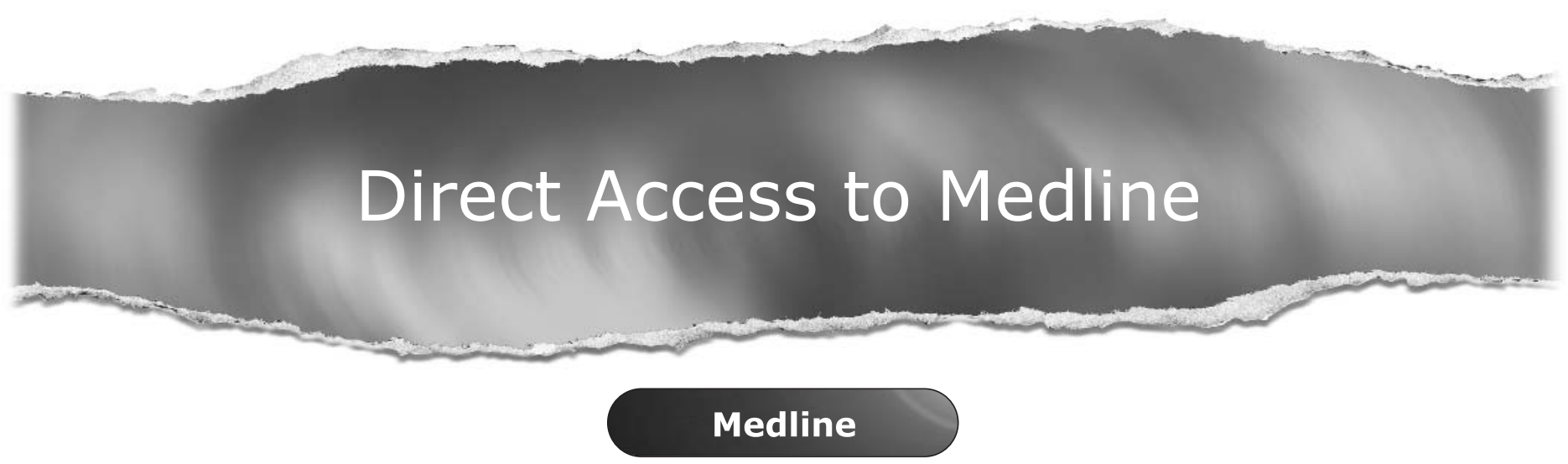

Link to Medline from the homepage and get straight into the National Library of Medicine's premier bibliographic database. Medline allows you to search across 9 million records of bibliographic citations and author abstracts from approximately 3,900 current biomedical journals.

\section{www.postgradmedj.com}

